REVIEW

\title{
Loretta M. Gaffney's Young Adult Literature, Libraries, and Conservative Activism
}

\author{
RACHEL MYERS \\ UNIVERSITY OF OKLAHOMA
}

At the heart of the ongoing debate about the merits of Young Adult literature is a fundamental assumption that informs a fundamental question. The assumption is that young people should read - this is not up for debate (except maybe by the young people themselves). The question, however, is not so easy: why should young people read? The answers to this question are as varied as the teachers, librarians, cultural critics, and parents who try to answer it. In her first book, Young Adult Literature, Libraries, and Conservative Activism, Loretta M. Gaffney explains and analyzes the different agendas that shape societal attitudes about young people reading, and specifically young people reading Young Adult literature. It is important to note that Gaffney is not advocating for any kind of conservative activism, but instead analyzing the ways in which YA literature has been a battlefield in the American culture wars that have been going on since the 1960s. She is taking an historical approach to YA literature to both legitimize it as a literary genre and to demonstrate that it has always had political underpinnings. Gaffney's main assertion is that by analyzing the attitudes and beliefs that people have about YA literature, we can better understand the "politics of reading" that shape discourses about adolescent reading, its importance, and its societal impact.

Gaffney begins with the chapter "How to Read a Young Adult Novel," which includes the attempt to define "Young Adult literature" that occurs in any conversation about the reading and writing of YA literature. For Gaffney, "Young Adult Literature" is a historically dynamic categorization that has shifted over time and taken on different meanings depending on who is talking about it. She looks at the history of adolescent reading and writing and the ways that those texts were used by adults to justify social/moral outrage against teenage behavior, particularly in times of great social upheaval. After effectively establishing the historical linkages between teen reading and social/moral outrage by adults, Gaffney moves on to the larger implications of this historical trend: how do we recommend and teach literature to young adults? As a librarian and a classroom teacher, Gaffney is in a somewhat unique position to see these issues from multiple angles. Her suggestion, which structures the rest of the book, is that there are three strategies with which to approach an understanding of various attitudes about YA literature: aesthetics, pedagogy, and pleasure. Gaffney explains 
these strategies are "loosely based on early youth librarians' criteria" of "morality, literary quality, and child appeal" (p.16). By adapting these early criteria into reading strategies, Gaffney offers readers of all ages a way to "navigate the cultural and political landscape of YA literature" (p. 16). This "navigation" is crucial at a time when YA literature has become a huge presence in American culture through both book sales and media adaptations. These strategies also offer ways to respond to those who critique YA literature for various reasons. Gaffney acknowledges that these strategies do not exist separately from each other, but that often people pick one over the other two when framing their discussions about YA literature.

Gaffney argues that using these strategies to identify attitudes and assumptions about teenage readers reveals the political nature of teen reading. By stepping back from the assumptions that reading is good for teens because it makes them more moral in some way, and instead interrogating "how teens are reading - or more to the point, how different ideas about how young people read bolster political conflicts - it highlights the politics of reading in ways that are fruitful for scholars and practitioners alike" (p.18). Gaffney is careful to define "politics" in such a way (the "exercise and maintenance of power relationships") so that she can then define the "politics of reading" as "shorthand for the competing values and ideologies, often tied to unequal power relations between and among groups such as parents, teenagers, educators, reading professionals, and institutions" (p.18). Gaffney then asserts that "...Teen reading and YA literature are contentious precisely because they are tied to questions of identity, power, and representation" (p.18). The main thrust of Gaffney's argument seems to be that the inherently political nature of YA literature necessarily makes it a proving ground for larger societal debates about identity, power, and representation.

Chapter Two, "Constructing the Teenage Reader," is particularly useful for anyone despairing at the state of teen reading. Gaffney deftly exposes the assumptions and attitudes about teens that often influence reading research, while also revealing the ways in which research questions and criteria can often inaccurately shape conclusions about teen reading. By taking a long historical view of teen reading, Gaffney is able to demonstrate that the current panic about lack of reading in the digital age is just another in a long line of educational panics that have plagued teens at least since the early $20^{\text {th }}$ century ( $\left.p .24\right)$. Alongside the cultural tendency to view anything teens are doing as suspect, methodological concerns also keep teen reading research from being a helpful source of information. Gaffney lists several issues that are preventing research on teen reading from showing the whole picture: "disciplinary parameters, methodological quarrels, and unexamined binaries between topics like informational and entertaining reading, assigned reading and voluntary reading, and print reading versus digital reading" (p. 25). She then gives each of these research issues their own section, explaining why these various problems hinder reading research. For example, she analyzes how the narrow definition of "reading" used by research from the National Endowment for the Arts reinforces the idea that "academic" reading and recreational reading are unrelated categories (p. 37). Gaffney also responds to cultural critics, specifically Mark Bauerlein's book The Dumbest Generation, to show how popular stereotypes about teen reading shape the discourse around teen reading research. She argues that the

\section{Study and Scrutiny: Research in Young Adult Literature}


definition of "reading" needs to be expanded to include academic, recreational, print, and digital reading to see a clearer picture of how much and what teens are reading (p. 38), and that the reasoning behind these limited definitions is political because it reinforces the idea that certain kinds of reading practices are more "academic" or "useful" than others. Allowing teens to determine their own reading practices generally leads to more engagement with the text, and Gaffney's claims here seem to suggest policy makers and educators are hindering teen reading by not allowing for a broad definition of "reading."

After thoroughly establishing the connections between teen reading, YA literature, and politics, Gaffney then moves into three chapters that detail each of the reading/analyzing strategies she established in the first chapter. In "Tending the Fair Garden: Canon Formation and Aesthetic Approaches to Young Adult Literature," she traces the history of young adult librarianship in order to show how the development of the youth librarian is connected to the desire for children and youths to read aesthetically powerful literature. Gaffney does not define "aesthetics" specifically, but instead shows how early youth librarians viewed literature as providing a way for readers to "transcend" their circumstances. This matters, Gaffney asserts, because "youth librarians - combing the tradition of progressive educators with the field's early and continuing allegiance to aesthetics and literary quality - tend to frame reading... as a transformative act" (p. 53). It seems that early youth librarians had the idea that reading canonical texts had the power to make readers "better" in some way. However, devotion to the canon suppresses reader choice, so Gaffney argues that this "transformation" through reading is no longer based on the power of words but on the power of readers picking the books they want to read (p. 53). Unfortunately, Gaffney does not really explain what "transformation" looks like, and in this section, she is speaking specifically about librarian practices (re: helping people select books), so the pedagogical implications of privileging the reader's choice over the author's canon membership are not explored.

Chapter Four, "Bibliotherapy and the Problem Novel: Pedagogical Approaches to Young Adult Literature," moves the conversation into the issues of teaching and recommending "realistic" YA literature to teens. Gaffney argues that while "bibliotherapy, or the practicing of 'prescribing' particular books for readers' problems has...fallen out of professional vogue...the subtle didactic emphasis of YA librarians' and teachers' professional literature reveal that various therapeutic approaches to the literature are alive and well" (p. 58). She then goes on to interrogate both what "realism" means in YA literature while also exposing the assumptions of YA literature's therapeutic uses that appear in both librarian and teacher discourses. Gaffney frames this discussion around the "problem novel" - books that depict life "problems" in didactic ways in order to teach the reader more about life. These novels are often accused of being too "dark" and "hyperrealistic," in that they highlight difficult experiences (e.g. Go Ask Alice) by going into specific, gritty detail about what those experiences are. Gaffney recognizes that this is no longer the practice in YA librarianship, but those didactic and prescriptive undertones still linger in discussions about the purposes of YA literature. As a side note, this chapter's title seems a little misleading - "pedagogical approaches," in this case, does not include

\section{Study and Scrutiny: Research in Young Adult Literature}


how YA literature is taught in the classroom. Instead, "pedagogical" is used to describe the tendency of librarians and teachers to use YA literature to "trick" teen readers into learning lessons from the books they read by disguising those lessons in books that are dark, edgy, and realistic.

Lastly, in "The Uses of Pleasure: Popular Literature and Young Adults," Gaffney exposes the negative connotations that pleasure reading still has for some cultural critics, tying this to larger societal arguments about why and what teens should read. She discusses the connection between pleasure reading and literacy, and the ways in which librarians and teachers have tried to push back against the notion that reading for pleasure is somehow "not enough" when it comes to teen reading. She also makes her case for reading as a political act more thoroughly in this chapter, comparing teen pleasure reading and book choice with research done on housewives reading romance for pleasure. Pleasure reading can be a radical political act when "escapism" is reframed as "an empowering act for readers who are disenfranchised in some way" (p. 84). Gaffney connects this to ideas about intellectual freedom and reading research, explaining how youth are much more likely to engage and enjoy reading when given the freedom to pick and explore texts for themselves without the intervention of adults (p. 91). Her assertion that reading is a political act of resistance makes sense when combined with the notion that intellectual freedom should be afforded to adolescents since reader choice does give teens an area of life that they can control and experience without adult intervention. Unfortunately, this reading-as-political-resistance is problematic for adults who are trying to police teen media consumption, and teens themselves, Gaffney argues, and YA literature has thus become a battleground for the culture wars happening in American society at large.

Gaffney has gone to the trouble of explaining these strategies in depth and connecting them to reading as a political act to reveal why conservative library activism even exists. Why would people fight about what books teens read if those books, and the act of reading, was not supremely impactful? Gaffney has already answered this question, and in Chapter Six, “'No Longer Safe': Young Adult Literature and Conservative Library Activism," she elucidates the consequences of conservative attitudes toward teen reading and the ways that conservative activists have pushed back against trends of pleasure reading and teen choice. Gaffney uses a few case studies to demonstrate how arguments against "bad" teen literature are often framed as moral issues by "pro-family" far-right Christian groups that oppose any positive depictions of LGBTQ people and teen sexuality, along with "realistic" problem novels (those perennially banned books) and anything else they decide is objectionable (p. 106). Gaffney traces the history of the pro-family Christian movement through its attempts to restrict different kinds of media, and particularly in its work against public libraries. She ultimately concludes that this long debate is a "conflict between 'sexual conservatives' and librarianship over the role of information, curiosity, and pleasure in human life...If sexual pleasure is safely corralled only by heterosexual marriage, then textual pleasure must also be corralled by the proper moral (and, ultimately, political) frameworks" (p. 115). This conclusion neatly summarizes the attitudes of the pro-family movement, and the reason why conservative activists have chosen the library, with its influence on teen reading, as a battleground.

\section{Study and Scrutiny: Research in Young Adult Literature}


Finally, Gaffney asks, where do we go from here? In Chapter Seven, "Do We Dare Disturb the Universe? Young Adult Literature and Social Change: A Conclusion," she uses her experiences of teaching Robert Cormier's The Chocolate War to frame a larger discussion about social activism and YA literature. YA literature has become a political battleground precisely because of its audience. Teens in America are more diverse in almost every category when compared to older generations: they are more likely to be non-white and more likely to identify as gay or to know people who do so (p. 121). These demographic shifts seem to have increased the dismissive rhetoric about adolescents coming from certain cultural critics, particularly those who do not think teens should have political agency. Gaffney then goes on the highlight the ways in which teens have become increasingly politically active. She points to Occupy Wall Street, student protests against school censorship, and the Black Lives Matter movement. She also lists a series of court cases, starting in the 1960s, in which teens challenged rules that limited their intellectual freedom, some particularly regarding banned books. Since adolescents are politically engaged in ways that older generations might find problematic, YA literature's association with teens makes it also problematic in political ways. Gaffney then points to the need to interweave the various ways that people read YA literature she discussed previously, arguing that a workable theory of YA literature and its readers must include elements of aesthetics, pedagogy, and pleasure to be truly effective.

Young Adult Literature, Libraries, and Conservative Activism is the product of Gaffney's twin professional interests: librarianship and English teaching. The book does lean more toward the library side of the equation, but that is perhaps to be expected, given that she has spent more time as a librarian than a classroom teacher. Gaffney's argument is complex with many pieces that she manages to fit together fairly clearly, giving the reader plenty of evidence for the ways that reading can function as a political act while narrowing in on the various ways that the category of "Young Adult Literature" has evolved and been challenged in American culture over the years. By taking a long historical view of these issues, Gaffney is able to more effectively tie them together. Part of the success of Gaffney's book is the deft way she synthesizes a huge variety of source material from library studies, English pedagogy, literary studies, and cultural criticism. This synthesis is important because often these different fields talk about the same topics without actually talking to each other, and Gaffney demonstrates that these diverse branches of scholarship, when taken together, can more effectively discuss the deep issues of reader/student choice, canonization, and the politics of reading. This book could serve as a useful primer for new scholars approaching the large and contentious conversation about teen reading and YA literature. Each chapter is thoroughly footnoted, and her extensive bibliography provides a starting place for researching the history of YA literature and cultural debates about teen reading. Her arguments feel apt at a time when the culture wars are raging in public schools as strongly as ever. 


\section{REFERENCES}

Gaffney, Loretta M. Young Adult Literature, Libraries, and Conservative Activism. Rowman and Littlefield. Lanham, Maryland. 2017.

RACHEL MYERS is a graduate student at the University of Oklahoma pursuing a Master's in Instructional Leadership and Academic Curriculum with a focus in English Education. Previously, she taught Freshman Composition at the University of Oklahoma and eighth grade Language Arts in Norman Public Schools. She is currently a full-time student and mother and hopes to return to the secondary classroom after completing her degree. 